\title{
In memoriam Ángel de Lucas, mestre de sociòlegs
}

Ángel de Lucas Matilla va morir el dia 27 de juny de 2012. Aquestes ratlles tenen com a objectiu recordar i retre un breu homenatge a qui, sense cap mena de dubte, forma part de les grans figures de la sociologia crítica espanyola.

Ángel de Lucas va néixer l'any 1929. Malgrat que el seu desenvolupament professional va estar sempre vinculat a les ciències socials, inicialment va estudiar la carrera de Matemàtiques, per més endavant cursar — com a segona carrera- Ciències Polítiques. De fet, tal com ell mateix observava en una entrevista feta l'any 1992, de forma un xic paradoxal, la formació matemàtica l'havia portat a desconfiar de l'aplicació dels models formals al camp de les ciències socials, justament perquè els matemàtics son els qui coneixen bé els límits dels models que ells mateixos utilitzen. D'alguna manera, aquesta formació inicial va servir a de Lucas per fer un ús crític de les eines d'anàlisi sociològica, així com per dedicar-se a un dels àmbits de la sociologia en els quals més s'ha destacat i on ha obtingut més reconeixement: el de la investigació qualitativa.

És a partir de mitjan anys seixanta quan Ángel de Lucas comença a dedicar-se professionalment a les ciències socials. En aquesta mateixa dècada, com tants altres de la seva generació, passa per la presó franquista a causa de la seva militància i del compromís contret contra el règim. Uns quants anys abans, per raons similars, ja havia estat expulsat de tot organisme oficial. Entre els anys 1965 i 1968 forma part del grup de professors que inicien l'aventura de CEISA (Escola Crítica de Ciències Socials de Madrid), escola de pensament i investigació sociològica de la qual sorgeix una bona part dels corrents dominants de la sociologia espanyola. Aquí coincideix amb sociòlegs de la talla d'Alfonso Ortí i Jesús Ibáñez, amb qui compartirà bona part de la seva carrera professional. L'any 1968, però, l'escola pateix un primer tancament, i l'any 1970, per ordre del Govern, es clausura definitivament.

Davant de la impossibilitat de desenvolupar-se com a investigador social a les institucions universitàries del país, a finals de la dècada de 1960, Ángel 
de Lucas s'integra a ECO, una de les primeres empreses d'investigació social i de mercats - fundada per Jesús Ibánez. Son els anys de transformació cap a la societat de consum espanyola, i és el context en què de Lucas, juntament amb altres investigadors, anirà configurant i posant en pràctica un model de sociologia qualitativa centrada en l'anomenat grup de discussió. Si bé és Jesús Ibáñez qui reflexiona, elabora i escriu, a Más allá de la sociología..., els fonaments d'aquest model, queda reconegut el caràcter col-lectiu de l'invent que constitueix la llavors innovadora pràctica investigadora. El grup de discussió suposa un avenç importantíssim per a la investigació social, en la mesura que obre la possibilitat d'analitzar la societat des d'una perspectiva més oberta a la que havia dominat fins aleshores. En aquests primers anys, el grup de discussió s'aplica a les investigacions de consum, concretament, a l'anàlisi de marques i productes comercials que, a la dècada de 1960, començaven a introduir-se amb força a la societat espanyola. Justament, el que permetia realitzar aquesta pràctica era captar els discursos socials i, a través d'aquests, les actituds i els desigs dels consumidors. De forma progressiva, el grup de discussió passa també a aplicar-se a la investigació sociològica institucional. Durant les dècades següents, Ángel de Lucas es dedica — com a freelance - a la investigació de mercats i d'opinió per a diverses consultores i institucions, per exemple ALEF — també fundada per Ibáñez. Expert en diverses metodologies i tècniques d'investigació, en una primera etapa, s'encarrega dels estudis quantitatius per passar posteriorment als qualitatius. Entre els estudis realitzats, en podem destacar l'encàrrec, per part del Centro de Investigaciones Sociológicas (CIS), d'un estudi qualitatiu realitzat l'any 1983 conjuntament amb Alfonso Ortí, precedent a la Llei de despenalització de l'avortament.

En dècades posteriors, ja iniciada la "transició postfranquista", Ángel de Lucas s'incorpora a la universitat exercint com a professor de Sociologia a la Facultat de Ciències Polítiques i Sociologia de la Universitat Complutense de Madrid, fins que es jubila. Molt probablement per la seva trajectòria biogràfica i professional, alguns dels seus àmbits d'interès principals, així com les matèries des d'on exerceix més influència en el seu paper d'ensenyant, han estat la sociologia del consum i l'àmbit dels mètodes i les tècniques d'investigació social. En tots dos camps, la lectura atenta de la psicoanàlisi freudiana, i especialment d'allò que se'n pot extreure per a la sociologia, ha estat un enriquiment constant de la seva transmissió de coneixements, malauradament per als seus lectors, més centrada en la via oral que no pas en l'escrita. En la seva labor docent, és especialment remarcable la cofundació i direcció del reeixit curs de postgrau Praxis de Sociología del Consumo e Investigación de Mercados... a la Universitat Complutense de Madrid, amb vint-i-dues promocions. Tal com s'ha dit algunes vegades, una de les virtuts de de Lucas i dels altres «mestres» que l'han acompanyat en aquesta tasca, ha estat fer d'aquest curs quelcom més que un postgrau universitari, perquè, al llarg de les diverses promocions que n'hi ha hagut, s'ha anat constituint com un dels nuclis fonamentals del corrent d'anàlisi sociològica ja més o menys conegut com és l'Escola Crítica de Qualitativistes de Madrid. 
Els qui han tingut la fortuna d'haver conegut personalment Ángel de Lucas, com a col.lega de professió o com a professor, l'han descrit com una persona amable, generosa, humil, i amb una profunda aptitud crítica i intel-lectual. De ben segur que la seva destacada capacitat d'escolta — tan important en l'ofici del sociòleg-i les seves sàvies i pausades paraules perduraran en la memòria de molts, com a exemple de consciència crítica i praxi sociològica.

Finalment, no podem deixar d'assenyalar que, probablement, el reconeixement públic que avui té Ángel de Lucas no es correspon a la rellevància de les aportacions que va fer a les ciències socials. En aquest sentit, recollim les impressions recents d'un exalumne del propi de Lucas a propòsit de la seva mort, afirmant que el pitjor que es pot fer amb els bons «mestres» és deixar-los caure en l'oblit.

Marc Barbeta Viñas

Universitat Autònoma de Barcelona marc.barbeta@e-campus.uab.cat 
